Neste artigo apresenta-se o conceito de "instituição estaurada" da Escola Experimental de Bonneuil-sur-Mame. Esse conceito pôde ser desenvolvido camo sua principal característica somente pela união da prática experimental desse instituto (que recebe crianças e jovens en dificuldade) cam teoriaspsicanalíticas, (pós-)estruturalistas e anti-psiquiátricas. Nesse contexto, as teorias psicanalíticas servem não samente para a análise das relações intersubjetivas, mas também de estruturas institucicnais. Dessa maneira, a "instituição estourada" abre a possibilidade de seguir um "trajeto no caminho do desejo", não somente para as crianças e os adblescentes, como também para os adultos que lá trabalham. Por último, este artigo mostra como essa instituição, cammais de 30 anos de existência, conseguiu encontrar saídas estruturais para resistir - cono "instituição estarada" - a cristalizaçães institucionais.

Instituição estarrada; jogo do Fort-Da; antipsiquiatria

THE "BURST INSTITUTION" AS A "FORT-DA GAME" - FROM JACQUES LACAN TO THE IDEA OF THE "BURST INSTITUTION" OF THE ÉCOLE EXPÉRIMENTALE DE BONNEUIL-SUR-MARNE

This article describes the idea of the "loust institution" of the École Expérimentale de Bomneuil-sur-Mame. This idea could became the École's smain characteristic only because the experimental practice of this institution (which receives children and juveniles inciffialties) is joined with psychoanalytical, (post) struaturalistic andatipsychiatrical theories. In "Bamevil", psychoanalytical theories are not only applied to the analysis of interpersonal relations, bat also helpunderstanding institutional struatures. In this way, the "laust institution" qpens the qpoortunity to go "a stretch on the road of wish" for the children and juveniles as well as for the adilts who work there. Finally, I show how this institution has - throughat and despite of its 30 years of existence as "arst instituti$a r^{\prime \prime}$ - managed to resist institutiarlsclessis.

Burst Institution; Fort-Da Game; Anti-Psychiatry

\section{A "INSTITUIÇÃO ESTOURADA" COMO "JOGO DO FORT-DA" \\ - DE JACQUES LACAN AO CONCEITO DE "INSTITUIÇÃO ESTOURADA" DA ESCOLA}

\section{EXPERIMENTAL DE BONNEUIL - SUR - M A R N E}

Miriam Anne Geoffroy

Tradução: Kelly Cristina Brandão da Silva

\section{BONNEUIL}

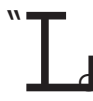

hnge de nós [...] a idéia de descrever um lugar ideal. É simplesmente isto: de um lugar à margem do estabelecido (como Bonneuil) é que se podem formular interrogaçães, ordenar uma pesquisa e viver uma experiência (Mannoni, 197383, p. 16)."

Psicóloga formada na Universidade Livre de Berlim. Doutoranda na Universidade Livre de Berlim sobre a École Expérimentale de Bonneuil-sur-Marne. 
Com essa máxima, Robert Lefort e Maud Mannoni, que foi, ao lado de Françoise Dolto, a psicanalista de crianças mais conhecida da França, fundaram em 1969 a Escola Experimental de Bonneuil-sur-Mbme, como parte integrante de um Centre d 'Études et de Recherches Pédagogiques et Psychanalytiques, istoé, um Centro de Estudos e Pesquisas Pedagógicas e Psicanalíticas (Mbnnoni, 1976-78, p. 11). Uma marca dessa instituição - desenvolvida ao longo do tempo - é seu conceito de "instituição estourada" (Nannoni, 1973-83, p. 71) , que deve ser apresentado neste artigo em relação à sua base té́rica.

A "escola experimental não-segregativa" (Manmoni, 197073, p. 236) Bonneuil (localizada no centro de Bonneuil-surMarne, um subúrbio de Paris), que é oficialmente reconhecido desde 1975 como hospital-dia, com alojamentos terapêuticos notumos e é financiado pelo Seguro Social, foi marcada por diferentes influências históricas, políticas e teóricas. Para isso contam o movimento antipsiquiátrico inglês e italiano dos anos 60, assim cono a Psychothérapie institutionnelle, que representa um dos mais importantes movimentos de reforma da psiquiatria francesa depois da Segunda Guerra Mundial. Do mesmo modo, Bonneuil foi influenciado pelos trabalhos de Michel Foucault, pelas análises de Erving Goffman sobre "instituições totais" e pelo movimento de 1968. E last but not least ${ }^{1}$ pela psicanálise lacaniana, que - no retomo a Freud - fomece as referências mais importantes para o conceito de instituição estourada. Bonneuil é assim uma instituição que tenta - com base em princípios psicanalíticos, (pós-) estnuturalistas e antipsiquiátricos - considerar o sujeito ao mesmo tempo como sendo formado pela sociedade e como um sujeito que vivencia a vida subjetivamente. Dessa forma, as conceitos psicanalíticos não são somente uti lizados para a compreensão das relações interpessoais, mas também para a compreensão de estruturas institucionais, pois a fundadora, Maud Mannoni, afirma que a "loucura" não é um "processo patológico", mas sim uma "reação da personalidade global a uma extraordinária e conflituosa situação de vida", que tem que ser vista também em relação às relaçães sociais (1976-78, p. 244) . Por isso são procurados em Bonneuil novos caminhos para a relação com a exclusão social da "loucura", enquanto se tenta, ao mesmo tempo, partir do sofrimento que é vivenciado subjetivamente pelas pessoas.

O pensamento de que uma instituição atenda a alguém, opõese ao princípio de Bonneuil. Bonneuil recebe "des enfants et des jeunes endifficulté", au seja, crianças e abblescentes em dificuldade. Neste caso, o acento encontra-se no "em" porque este "em" indica - ao contrário da expressão "crianças com dificuldade" - que se trata de uma condição que pode ser alterada, e não de uma 
maneira de ser do sujeito que seja imutável (cf. Buhmann, 1990).

Muitas das crianças e adolescentes recebidos em Bomneuil tiveram ou têm dificuldades para simbolizar experiências de perda e - em conseqüência disso - de se constiturrem como sujeitos desejantes. Por isso em Bonneuil tenta-se oferecer a essas crianças e adblescentes possibilidades de vivenciar ou recuperar processos de simbolização. Com isso é dado um valor especial ao fato de que os adultos não desejem no lugar deles (crianças e adolescentes). Se Bomeuil, em princípio, pode ser útil para "todas" as crianças e os adblescentes que se encontrem em dificuldade, é uma questão que repetidas vezes é discutida - também em Bonneuil.

As crianças e os adolescentes recebidos em Bonneuil podem ser divididas em três grandes grupos, de acordo com categorias médico-diagnósticas, a saber, en "psicóticos", nas quais crianças e adblescentes autistas também são incluídos; os assim chamados debiles, isto é, em crianças e adblescentes mentalmente deficientes e em "neuróticos", au seja, em crianças e adblescentes que apresentem dificuldades de aprendizagem e/ou acentuados distúrbios de comportamento. Mas o importante é que as categorias diagnósticas desempenham um papel apenas na receppção das crianças e dos adolescentes e não no dia-a-dia de Bonnevil, porque deve ser dada às crianças e aos adblescentes a passibilidade de poderem construir relações com o outro que não sejam influenciadas nem por essas categorias nem por autros preconceitos. As catego- 
rias são consideradas somente na entrada, pois há a necessidade de que haja um equilíbrio no tamanho dos três gnupos, para não favorecer o predomínio e a repetição de determinados sintomas, ou de tipos de sintomas. Além disso, parte-se do princípio de que as crianças possam aprender pelas formas de comportamento e projetos de outros.

As crianças e os adblescentes de Bonneuil têm entre 6 e 20 anos, excepcionalmente até 25 anos. É crucial que haja um limite de idade, pois Bomneuil pode e deveria ser também "recusada e contestada" (Mannoni, 1978, p. 51) . O objetivo de Bonnevil é, a saber, que cada criança com o apoio inicial de adultos - desenvolva e ambicione um projeto de futuro próprio fora de Bonneuil e, se passivel, também fora de instituições au "instituições totais" (cf. Buhmann \& Keimig, 1991, p. 115) .

\section{O CONCEITO DE "INSTITUIÇÃO ESTOURADA"}

Ao longo dos primeiros anos dessa institurição, que se definiu desde o começo como uma instituição aberta, cristalizou-se a noção de "instituição estarrada", entre autros motivos, como resposta à declaração de uma criança de Bonneuil que queria deixar a école des dingues, a "escola dos loucos". Essa declaração estava ligada ao desejo de se confrontar com o "mundo normal", e se queria levá-lo em conta. Assim, tomando a sério o desejo da criança, tentou-se acompanhá-la no risco de deixar a proteção da instituição e enfrentar a vida fora (cf. Buhmann, 1990, p. 15; Lérès, 2002). A noção de institutionéclatée (institurção estarrada) apareceu por escrito, pela primeira vez, em 1973, no livro de Maud Mannoni Éducation impossible (1973-83, p. 71) .

O conceito de instituição estarrada não é fruto de nenhum modelo teórico fixo que é aplicado à prática. Esse conceito representa como Significante - um processo aberto. Esse conceito desenvolveuse por uma dialética contínua entre as experiências reunidas e a tentativa de encontrar respostas - em especial, com a ajuda de conceitos psicanalíticos - para as perguntas que se apresentaram durante esse processo. O desenvolvimento desse conceito foi possivel porque Bonnevil, desde o começo, definiu-se como um lugar experimental, neste caso "experimental" significa que a instituição não é um lugar onde os regulamentos tradicionais são aplicados e, sim, um espaço em que foram deixados lugares vazios para o imprevisto, para que lá possa se passar "alguma outra coisa" (Mannoni, 197678, p. 50)

Mas, como se pode imaginar uma instituição estarrada, uma instituição que afirma que quer ser diferente das demais institurições, que praticamente se relacionam com os sujeitos que the são confiados de uma maneira onipotente e se comportam assim como a primeira pessoa de referência Ersste Bezugspersan? de um psicótico? (Lefort qp. cit. Mannoni, 1976-78, p. 49) Pois nessas formas de "instituições totais" como Goffman as chama - o sujeito 
não pode desligar-se em nenhum momento da instituição, sem que isso arrisque seu próprio "estarro"3 psíquico.

Para responder a esta pergunta, as referências psicanalíticas que são essenciais para Bonnevil têm que ser apresentadas. En primeiro plano estão o conceito freudiano do "Fort$\mathrm{Da}$ " e o conceito lacaniano de "Simbólico".

\section{O "JOGO DO FORT-DA" COMO SIMBOLIZAÇÃO ORIGINAL}

O "Jogo do Fort-Da", que Freud descreve em Além do princípio do prazer (1920), não é somente fundamental para a teoria lacaniana do Simbólico, mas também para a prática em Bonnevil, que se caracteriza por um permanente ir e vir entre o centro da instituição e diferentes lugares. Uma parte desses lugares pertence à instituição e autra parte é independente dela.

Em Além do princípio do prazer, Freud descreve como uma criança de um ano e meio, que nunca chorava quando sua mãe a deixava por várias horas, repetia incansavelmente um jogo que consistia em fazer desaparecer e reaparecer dojetos: a criança deixava cair da beira da cama um carretel de madeira que estava ligado a umbarbante e dizia o-o-o-o, em seguida ela puxava o barbante novamente para si e alegrava-se com o ocorrido com um feliz "Da". Freud interpretou esse jogo em relação à "grande dora cultural" da criança, que é suportar a saída da mãe sem se opor a isso, ou seja, renunciar à satisfação da sua pulsão. A criança pôde colocar em cena ativamente, com o desaparecimento e o retomo do seu brinquedo, o desaparecimento e o retomo da mãe - que a criança tinha que aceitar passivamente. A criança encena nesse jogo o que ela sofreu passivamente com a ajuda de objetos e reconhece seu próprio papel de objeto na relação com sua mãe. Dessa maneira ela (a criança) abre para si um caminho para poder ocupar, ela mesma, um papel de sujeito.

Como Lacan sublinha, a relação do "eu" como outro é, emprimeiro lugar, uma relação de "objetivação" (Mbmnoni, 1973-83, p. 72) . Isso significa que a criança - no momento do seu nascimento - se insere como objeto em uma "ordem simbólica" (ou seja, a ordem da Linguagem e do Inconsciente) , pois recebe primeiramente um lugar somente nos desejos e fantasias da primeira pessoa de referência. A criança só poderá advir como sujeito, quando descabrir que a realidade é organizada através de uma ordem simbólica. E essa descoberta cai junto com a descoberta da "organização fonética da realidade" (au seja, coma aquisição da fala) , como nós pudemos observar de maneira exemplar no "Jogo do Fort-Da" (idem.)

Nesse sentido, O "Jogo do FortDa" representa um exemplo para a introoução de uma simbolização original. Ná repetição incansável do jogo acima descrito vinaula-se o som o-o-o-o, que foi compreendido pelos adultos (em concordância) como "Fort" (ausente), com o deixar desaparecer ou com a ausência do car- 
retel, e o som "Da" (presente) com o retomo ou a presença do brinquedo. A criança faz neste exemplo - através da repetição incessante do jogo - uma conexão entre os dois diferentes Significantes ("○-O-o-d" e "Da") e os Significados (as idéias de "ausência" e "presença") que estão numa relação arbitrária, ou seja, sem uma ligação evidente. Com base em processos como esse, a criança apreende a língua. Mas isso somente é possível na medida em que tanto os Significados se diferenciem, quanto haja uma diferença entre os Significantes (aqui: "ausência" 1 "presença"; ; ০-০O1 "Da") (Vanier, 1998, p. 68-73) .

Ao mesmo tempo, a criança constitui-se como sujeito, au seja, como aquele que exprime os Significantes (০-০-০-০, "Da") . Nessa posição de sujeito, a criança se encontra separada do "Autro", porque o carretel representa não somente a mãe ou a primeira pessoa de referênciat, mas também um objeto, do qual o sujeito se sente separadb. Emprimeiro lugar, a criança toma esse dojeto como "substituto" para a ausência da mãe, para a falta produzida aqui e tenta, então, inconporar esse dbjeto. Mas a ausência repetida da mãe introduz uma diferença, que leva à marcação significante de diferentes estadbs e faz do sujeito um sujeito separadb. A criança não pode definir-se mais como uma unidade com sua mãe, mas se diferencia e se encontra separada dela. Nãe e criança estão em uma "oposição significante" (qqposition signifiante, idem., p. 70) . Através do processo de simbolização, a mãe se toma um "objeto perdido" (objet peroul, idem, p. 72) . O que permanece é um resto, um fragmento, que Lacan chama de "objeto a". (Lacan, op. cit., p. 72) É crucial aqui que o dbjeto não se tenha tomado dbjeto perdido em conseqüência da ausência da mãe - ainda que essa condição exista - , mas sim, graças ao processo de simbol ização. O dbjeto tomou-se ausente porque foi substituído por um símbolo (idem, p. 73) .

De agora em diante, esse "dbjeto a" serve como orientação na vida do sujeito: Ele tenta reencontrar esse "dbjeto a" perdido. Mas o paradoxal desse objeto é que ele aparece, como "objeto a" somente depois da sua perda. Anteriormente, o dbjeto não podia estar separado do que ainda não era sujeito. A partir desse momento, no qual o sujeito faz uso da língua e, ao mesmo tempo, que o objeto aparece como objeto perdido (ou seja, objeto da falta) , não resta ao sujeito nenhum outro meio para reencontrar esse "dbjeto a" do que a língua. Nessa busca, cuja resolução bemsucedida representa-se como impossível, outros objetos podem colocar-se no lugar desse "dbjeto a" perdido, pois a simbolização abre a possibilicade da substituição: Agora o sujeito pode "desejar"! ! Mas o désir (desejo) supõe a renúncia de uma parte da jouissance (satisfação) . Essa renúncia é introduzida pela "castração simbólica" (idem, p. 68-73) . 
O "DESEJAR" E A

"CASTRAÇÃO"

Como advém o desenvolvimento do próprio desejo, se, primeiramente, o lugar que o futuro sujeito ocupa no discurso do primeiro outro é determinado pelo desejo do atro?

A interpretação de Lacan do Complexo de Édipo, como exemplo de uma castração simbólica, oferece-nos uma resposta: a mãe (ou a primeira pessoa de referência) atribui ao nascimento dessa criança um lugar que é causa de seu próprio desejo. Ao mesmo tempo, a criança depende do desejo dessa pessoa de referência. Mãe e criança encontram-se em uma "relação dual imaginária" . A criança espera e acredita poder satisfazer o desejo da mãe e compensar a sua falta, a seja, ser o seu "falo imaginário" (phallus imaginaire), enquanto a mãe crê que possui o falo imaginário (Nasio, 1988, p. 54f).

O dbjetivo da castração simbólica é fraturar essa relação dual imaginária pela intervenção de uma terceira instância, pois relações duais imaginárias não são somente amorosas e fascinantes, mas também dependentes, agressivas e - se elas forem duradouras - até mesmo mortíferas (p. 90; Vanier, 1998, p. 45) . No Complexo de Édipo o "pai" como representante da Lei (do tabu do incesto) - impede ou castra essa relação dual imaginária entre a mãe e o filho. A castração impede uma forma de satisfação (o imaginário Ser-Um entre mãe e filho), mas ao mesmo tempo introduz o sujeito no 
mundo do desejo. Isso significa que a satisfação fálica (em um sentido sexual amplo) é permitida (como única satisfação) pela Lei e é possível pelo reconhecimento da Lei (Vanier, 1998, p. 61f). Pela identificação - que acontece durante esse processo - da criança com o "pai"s como "portador da palavra, que significa a Lei" (Ruhs, 1980, p. 892), a criança entra na ordem simbólica, na ordem da Linguagem e do Inconsciente. A criança se descola de sua pasição de objeto e ocupa dentro da ordem simbólica um lugar como sujeito desejante.

Como ato simbólico e inconsciente, a castração representa uma Lei não pessoal, mas estruturada e estruturante, da qual o dojeto é imaginário. No caso do Complexo de Édipo, o "pai" ocupa o lugar de castrador, mas essa função pode aparecer em muitas autras variaçães (e isso será muito importante para a compreensão de Bonneuil) : Assim como um exame que tem que ser realizado, como um obstáculo a ser superado, ou como uma decisão que deve ser tomada. Todas essas instâncias castradoras cotidianas reatualizam a força separadora de um limite simbólico, sem que o sujeito esteja consciente disso (Nasio, 1988, p. 50-56) .

Como nós podemos ver no exemplo do "Jogo do Fort-Da", aqui também a castradora "Lei do Pai" representa a condição para ativar o processo de simbolização. O "Jogo do Fort-Da" como simbolização original scmente pôde ocorrer porque a criança teve a experiência da falta: A mãe estava ausente repetidas vezes. Mas sua ausência está ligada ao fato de que ela (mãe) possui outros desejos. Isso significa que ela mesma ocupou um lugar na ordem simbólica e vivenciau o processo de castração simbólica. O desejo da mãe é regulado assim pela "Lei do Pai". Durante o "Jogo do Fort-Da" a criança sente as ações de ir e vir da sua mãe, mas não consegue relacioná-las a nenhuma regra ou lei como ações arbitrárias. Essas ações arbitrárias serão substituídas inconscientemente ao longo do "Jogo do Fort-Da" pela "Lei do Pai" - que é introduzida pela ausência da mãe - como Significante que introduz a lei (Vanier, 1998, p. 62f).

A entrada na linguagem e a formação do inconsciente, que se relacionam com o reconhecimento da ordem simbólica e formam as condições para poder desejar, somente são possiveis porque o futuro sujeito vivenciou uma falta que pode ser simbolizada. Por isso Lacan afima que a falta é causa do desejo! (Mamnoni, 1973-83, p. 80). Se essa falta não pode ser vivenciada porque os pais de uma criança (ou a instituição) devoramo sujeito - au seja, vêem sua própria existência ameaçada por qualquer pequena tentativa de separação, de forma que a criança arrisca seu próprio "estarro" psíquico - então a criança pode não encontrar um acesso ao seu próprio desejo. Se a criança puder encontrar um acesso próprio ao seu desejo, a seja, se ela puder ocupar um lugar enquanto sujeito na ordem simbólica, depende em que medida as primeiras pessoas de referência (au instituriçães) ofere cempossibilidade à criança de vivenciar experiências de falta a percả que passam ser simbolizadas. É necessá- 
rio considerar que essas experiências simbol izáveis diferenciam-se emprincípio de experiências repentinas, nãosimbolizáveis, au seja, de experiências traumatizantes de perda. En resumo, isso significa que nem a primeira pessoa de referência nem uma instituição deve se colocar numa posição cnipotente frente à criança, se não quiser se comportar como a primeira pessoa de referência de umpsicático.

A "INSTITUIÇÃO

ESTOURADA" COMO

"JOGO DO FORT-DA"

Com base nesses conceitos psicanalíticos (que foram transferidos das relações intersubjetivas para as relaçães instituição-sujeito) e as experiências que foram feitas em conjunto comas crianças e os adblescentes de Bonneuil, desenvolveu-se em Bonneuil a idéia de que a institurição estourada tem que assumir ela mesma um "estouro", sem que a existência da institurição seja ameaçada, para assim dar a possibilicidade ao sujeito (au seja, às crianças e aos adblescentes que têm dificuldades para simbolizar experiências de perca) , de se parar-se da instituição, semarriscar seu próprio "estarro" psíquico, porque assim é permitido ao sujeito vivenciar experiências de falta que possam ser simbolizadas, au seja, exeattar cortes simbólicos. Sendo fenâmenos simbólicas, esses cortes que se realizam de acordo com o modelo de castração simbólica da relação mãecriança, aqui transferida para a rela- 
ção instituição-criança, permitem ao sujeito "advir e ser reconhecido como sujeito pelo outro" (Lefort, apud Mannoni, 1976-78, p. 49). Assim as crianças e os adblescentes de Bonneuil podem aprender gradualmente, por exemplo, por estadas de longa duração, adaptadas ao ritmo das crianças e dos adblescentes, nas famúlias acolhedbras da província e por pemoites regulares emum dos alojamentos notumos, a simbolizar experiências de perda (Mannoni, 197678, p. 237) .

O conceito de instituição estourada permite às crianças e aos adolescentes de Bonneuil "jogar" repetidas vezes o "Jogo do Fort-Da" como simbolização original e ter outras experiências, que têm a função de castrar - como o "pai" no Complexo de Édipo - a jouisssance original e deixar nascer o desejo (fálico). Os problemas que essas crianças e adblescentes em dificuldade têm com tais experiências mostram "diferentes conotações, dependendo de se tratar de uma criança - como se diz - neurótica ou psicótica" (Mannoni, 1973-83, p. 75) . Com isso Maud Mannoni afirma - o que pertence às inovações substanciais que ela introouziu no trabalho psicanalítico -, que nas chamadas crianças "deficientes mentais" fatores semelhantes como na psicose determinam a compreensão de si mesmas dessas crianças e suas relaçães com as outros. (Buhmann, 1994, p. 39-42; Mannoni, 1964-72, p. 138ff).

Mannoni descreve o significado do "Jogo do Fort-Da" para o conceito de instituição estaurada, como segue: "'O jogo do Fort-Da' , au essa ascilação entre um 'aqui' e um ' 'á', é introduzido na escola experimental de Bomeuil toola vez que a estada aí de uma criança se efetua em altemância com uma estada fora, em outro lugar [...] Juntamente com o ir-e-vir oferece-se um espaço significante, em que a criança é levada a perder-se para se lhe propiciar a ilusão de renascer aí, sustentando-se como sujeito pelo jogo de escansão presença-ausência. Em contraste com o que se passava no 'Fort-Da', a mãe não parte; mas a criança é colocada em situação de deixá-la e de deixar Bonneuil. Mantém-se idêntico o tipo de discurso que se tema partir de uma presença perdida" (Mannoni, 1973-83, p. 73).

É crucial que um outro lugar não seja somente um lugar geográfico, mas que haja simuma "dialética de presença e ausência" (idem, p. 74). É importante que as estadas alternadas em lugares diferentes "não sejam introduzidas de qualquer forma ou em qualquer momento, ou se tornem mero objeto de uma regulamentação administrativa" , mas sim que elas se orientem pelo ritmo da criança (idem) .

Sendo uma instituição, Bonneuil se coloca à disposição, por um lado, como um lugar de recolhimento protegido, mas, por outro, não se cansa de referir que Bomeuil não é tudo, que há um fora da instituiição: "Em vez de oferecer permanência, a estrutura da instituição oferece, sobre uma base de permanência, aberturas para o exterior, brechas de toodos as gêneros" (idem, p. 77) . Conseqüentemente, 
é relevante que Bonneuil seja designado simultaneamente como un lieu pour vivre (um lugar para viver) e como un lieu de passage (um lugar de passagem). Isso significa também que Bonneuil não oferece nenhuma proteção definitiva, segura, pois Bonneuil pode e deve ser deixada algum dia.

Para deixar Bonneuil e colocar-se na vida, é necessário ter tido a experiência de contar para outros, ou seja, que se receba um lugar como sujeito na ordem simbólica. Se este lugar, que somente pode ser dado pelo outro, oferece um espaço no qual a criança seja notada, ou seja, no qual seja ouvida, então ela pode surgir como sujeito.

Se as crianças e os adolescentes em Bonneuil podem ter a experiência de que são importantes para alguém, mesmo se eles não estiverem lá (fisicamente) , ou seja, de que eles continuam a existir ou são importantes nas representações e narrativas dos outros e de que os outros não sucumbem em sua ausência, então abre-se um caminho para expressar os próprios desejos e viver a própria vida. Durante sua presença, as crianças e os adolescentes são auvidos, pois a instituição estourada quer ser - semelhante a um analista - um "lugar de fala" (Mannoni, 1976-78, S. 237) , pois, pela escuta pode-se dar a possibilidade à criança de reconhecer "o que o sintoma fala dele" (idem, p. 51).

Pelas aberturas da instituição estourada, para fora de seu enquadre, surgem espaços em que o inesperado pode acontecer, - que também está ligado a riscos e dificuldades que têm que ser superados. E, como foi mencionado anteriormente, esses "testes de vida", que também sempre podem incluir perigos, desempenham a tarefa de confirmar a experiência originária de castração. Por isso, Mbmoni insiste em que o "direito ao risco", que é negado nas outras instituições - porque nelas deve ser oferecida uma perfeita segurança - seja garantido em Bonneuil (Mannoni, 197383, p. 10). Cada um têm o direito de viver sua vida e isso significa também ter a possibili idade de levar em conta riscos, pois a vida aguarda fora, fora das instituições fechadas e protegidas, com todbs seus perigos e todas suas riquezas.

\section{A PERMANENTE POSIÇÃO QUESTIONADORA DA INSTITUIÇÃO}

A abertura da instituição para o exterior desempenha também a importante função, entre outras, de colocar a instituição em permanente questão. Isso abrange o "desvelamento da fun- 
ção", que uma criança que se encontra em dificuldade tem para os outros (por exemplo, para os pais ou a instituição) (Mannoni, 1973-83, p. 77) , pois, como Mannoni mostrou, essas crianças desempenham freqüentemente uma função significativa para a existência dos outros. Assim elas podem absorver, por exemplo, os medos e problemas dos pais, o que pode manifestar-se, na preocupação exclusiva em tomo dos cuidadas físicas da criança.

De maneira semelhante - como em tais relações asfixiantes pais-criança - as crianças "doentes" desempenham a função de justificar a existência da instituição. Se a preocupação de uma instituição tradicional é somente com seu funcionamento eficiente e sem atritos, então a criança somente pode servir como "doente", como "garantidor da instituição" (Roedel, 1986, p. 120) . Por isso Mannoni afirma, que "toda instituição que não tem attros interesses além das interesses intemos [... tem efeitos mortíferos" (Mannoni, 1973-83, p. 166) . E esclarece que, como em toda relação dual, imaginária e narcísica, age também a relação "mortífera" dual entre instituição e paciente, se nenhuma terceira instância intervier.

Essas relaçães e estruturas duais tendem a uma imobilidade, a uma permanência e a repetições que Mannoni designou como "esclerose" (Mannoni, 1973-83, p. 39). Isso vale como impedimento não scmente na instituição estourada, pois elas conduzem ao exercício da força e da violência. Por isso leva-se em consideração em Bonneuil, que uma permanente posição questionadora da instituição possa oconrer.

Nesse sentido, deveria ser levado em conta em Bonneuil, por exemplo, que o sustento e o "sentido da vida" dos adultos que lá trabalham não sejam assegurados somente por Bonneuil: Isso significa que eles têm fora de Bomeuil uma ou mais bases profissionais. O grande número de estagiários, que por definição têm sua base (formação, estudo) fora de Bonneuil, desempenha um papel decisivo nesse contexto.

A importância de Bormeuil como centro de pesquisa pedagógico e psicanalítico toma-se aqui particularmente clara, porque pela grande quantidade de reuniões e projetos de pesquisa que lá acontecem oferece-se permenentemente a possibili idade de se questionar a institurição.

Como toda instituição, Bonneuil se defronta continuamente com dificuldades e contradiçães e, por isso também, com problemas interpessoais. Mas a particularidade da instituição estarrada é que ela tenta levar em conta - por definição - a existência dessas dificuldades e inconpora esse processo reflexivo também nas funções institucionais (e não scmente nos ideais dos empregados) . 
Por isso Bonneuil é um lugar que não somente pode ser questionado, mas que é dependente de ser colocado sempre em questão.

\section{PSICANÁLISE FORA DA INSTITUIÇÃO}

Uma outra característica essencial da instituição estourada é sua referência à psicanálise que no sentido mais verdadeiro da palavra - fica fora do "enquadre", ou seja, sua opinião sobre sessões de análise dentro de instituições clínicas é extraordinária: Em Bonneuil não se faz nenhuma análise, mesmo que "tudo o que aí se faz baseie-se rigorosamente na psicanálise, à qual não se recorre como técnica suplementar, mas como subversão de um saber e de uma prática" (Mannoni, 1973-83, p. 13) . Mannoni rejeita que sessões de análise ocorram dentro da clínica porque encara isso de forma particularmente problemática por dois motivos: por um lado, os pacientes veriam no psicanalista um cúmplice da instituição e sentiriam, eventualmente, as sessões de análise como um interrogatório ou duvidariam da boa intenção do psicanalista (Mannoni, 1970-73, p. 93). Por outro lado, os pacientes também tentariam - caso eles mudassem durante as sessões de análise - abrir brechas dentro da instituição. Mas a instituição não estaria em condições de sustentar essas brechas e então isso (o fato de não poder sustentar) poderia conduzir a um acting out ou a uma passage a l'acte (Kupfer \& Fleck, 1998, p. 41-46; Mannoni, 197073, p. 89-95) . "Não se pode querer libertar a linguagem dentro da instituição psicanalítica (ou seja, dentro da sessão de análise, M.A.G. ) sem que isso não leve a conseqüências no exterior, ou seja, dentro da instituição social (dentro da instituição psiquiátrica, M.A.G.) à qual a instituição psicanalítica se encontra presa (Mannoni, 1970-73, p. 91) . Mannoni afirma que a clínica psiquiátrica, que é sentida pelos pacientes como uma prisão, não é o lugar no qual seria permitido propagar um livre falar" (idem, p. 95) . Ela (Mannoni) retira dos disarrsos antipsiquiátricos a idéia de que a fala da loucura somente possa ser libertada se ela apresentar-se publicamente, ou seja, se ela apresentar-se fora do enquadre institucional (Mannoni, 1973-83, p. 148) .

Na instituição estourada, há possibi 7 idade para crianças e adblescentes fazeremuma análise; mas isso ocorre fora de Bonnevil, principalmente em Paris. Dessa maneira, as instituiçães "sessão de análise" e Bomneuil são estruturalmente e espacialmente separadas (Kupfer \& Fleck, 1998, p. 41-46) .

\section{A PRÁTICA DA}

INSTITUIÇÃO ESTOURADA

O princípio do "Jogo do FortDa" reflete-se em Bonneuil sobretudo na escansão entre o ir e vir, entre o centro da institurição, au seja, o hospital-dia, que é chamado de éco- 
le (escola), eatros diferentes lugares fora da école, que estão diretamente ligados à instituição (como, por exemplo, os alojamentos notumos) ou são independentes dela (como, por exemplo, as fanúlias acolhedoras) . O centro da instituição oferece-se como lugar de recolhimento, mas a vida acontece principalmente fora da école. É cnucial que as crianças e os adblescentes, antes de irem "fort" por um tempo, tenham tido a experiência de pooler estar "da" na école, ou seja, que eles tenham encontrado em Bomneuil um lugar (simbólico) para eles, que um lugar des sujeito lhes seja reconhecido pelos outros (Buhmamn 1990, p. 13ff; Mannoni, 1973-83, p. 76) [(Mannoni, 1973, p. 82) ] .

Com base no conceito do "Jogo do Fort-Da", faz parte dos elementos essenciais da instituiçãa estaurada que muitas crianças e adolescentes passem regularmente algumas semanas na casa de famílias acolhedoras no interior, principalmente no sul da França. Sobretudo para crianças psicóticas - às quais no passado não foi permitido nenhum lugar para a experiência da falta - existe aqui a possibilidade de vivenciar, pelas separações temporalmente limitadas de Bonneuil e em especial dos pais, uma perda simbólica, que pode permitir às crianças um acesso ao próprio desejo.

Quando as crianças e os adblescentes vão para suas famúlias acolhedoras, separam-se freqüentemente pela primeira vez por um período longo de seus pais. Muitos pais que ainda vivem a instituição freqüentemente como um prolongamento deles mesmos, sucumbem ao fantas- 
ma de ter ainda, através da instituição, a "onipotência" sobre o corpo da criança. Os pais não podem ter a sensação de se separar do fi lho antes de as crianças deixarem Bonnevil e irem para seus pais acolhedores. Os pais sentem dores de separação Tremmungsschmerzen, têm a sensação de que não têm mais o poder sobre a criança. Para que essa separação passa ser assimilada simbolicamente pelas crianças e pelos pais, énecessário que as separações sejam altemadas, ou seja, que ambos tenham a experiência de que vão se reunir de novo, porque o dbjetivo não consiste em separar a criança para sempre de saus pais, mas simque ela (a criança) possa reaperar a experiência da "falta".

Pela altemância regular entre presença e ausência, as crianças podem também ter a experiência de que mantêm um lugar em Bonneuil. Elas sabem que durante a sua ausência (física) são falados como membros da école, pois durante a ausência de outras crianças e adolescentes os presentes chegam a saber que os ausentes não são esquecidos: é conversado e relatado sobre eles, nas atividades nas quais eles faltam, seus nomes são mencionados etc. Contudo, ao mesmo tempo eles vivenciam que o dia-a-dia em Bonneuil segue seu curso. Assim, podem vivenciar que têm um lugar em alguma parte, que eles contam para outros, e que tudo não sucumbe na ausência deles (Buhmann, 1990, p. 13ff; Mannoni, 1973-83, p. 80-83) [ (Mannoni, 1973, p. 86-89) ] .

Nas viagens para as famílias acoThedoras, assim como nos acampamentos de verão (mas também em 
pequenas saídas, por exemplo para os analistas), as crianças têm freqüentemente decisivas experiências (de separação) pouco antes da partida ou no caminho entre o Fort e o "Da" (ou o "Da" e o "Fort") . Por isso é também importante que elas sejam acompanhadas nesses caminhos por um adulto. Ocorre freqüentemente, por exemplo, que as crianças e os adblescentes no fim de um acampamento, de uma estada nas famúlias acolhedoras ou na volta de carro ou de trem entrem em crise, o que pode ocorrer na forma de agitação, agressão ou recolhimento (Buhmann \& Keimig, 1991, p. 103-07).

É surpreendente que algumas crianças que nunca ou quase nunca falam, expressem aqui pela primeira vez palavras que não possam ser chamadas de ecolalia - ou seja, como repetições automatizadas -, mas sim de "fala cheia". Assim, por exemplo, Pierre ${ }^{6}$, um adolescente de 10 anos, que usava as palavras quase sempre na forma de ecolalia, pouco antes da saída de seu primeiro acampamento e no fim de uma grande crise, em que estava muito furioso, gritava e se batia, disse a frase: On a marre papa, que na sua ambigüidade pode ser traduzida samente de forma aproximada como "Está farto papa", ou "Está farto do papai" (Geoffroy, 2002, p. 111).

Pertencem ainda a Bonneuil, além da école, três apartamentos separados e uma casa, que se encontram distantes algumas ruas umas das outras (e da escola) . Como alojamentos notumos, eles oferecem a possibil lidade a três au quatro crianças e adolescentes durante a semana e de forma reduzida também no fimde-semana, de experimentarem - em pequenas etapas - uma separação provisória dos pais, o que contribui na gênese do sujeito e pode preparar uma separação mais longa, por exemplo, uma estada em uma família acolhedora. Ao mesmo tempo, eles podem ter uma experiência adicional de separação nos alojamentos notumos: A cada ano escolar, há um grupo fixo vivendo junto em cada moradia. Após o ano o grupo se dissolve. Assim o alojamento notumo apresenta-se por um lado uma permanência, mas ele também indica que no fim do ano acontece uma separação, que algo novo ocorrerá depois (Fleur et al. 2000) .

Além da estada nas famúlias acoIheobras, o travail à I 'extérieur (trabalho fora) é uma das características mais importantes de Bomeuil: Quase todas as crianças e adblescentes de Bonneuil - independente da idade e de suas dificuldades - vão trabalhar fora no mínimo uma vez por semana. Os lugares de trabalho, que são procurados e selecionados de acordo com os desejos das crianças e dos adblescentes, são principalmente pequenos estabelecimentos artesanais, como padarias, floriculturas, restaurantes, oficinas de carro audebicicleta.

Mas o objetivo desse trabalho fora não é que as crianças e os adolescentes sejam preparados para uma profissão. Abre-se para alguns jovens desse modo uma perspectiva profissional, mas que é somente um "efeito positivo paralelo" . A função essencial do trabalho fora encontra-se no fato de as crianças e os adolescentes poderem ter a experiência de 
dividir com alguma outra pessoa uma atividade. É de central importância que um "encontro" (rencontre) , que possa ocorrer por um interesse comm, se realize, porque a atividade comm - ocupando a função de uma instância castradora - impede nesse encontro um relacionamento imaginário dual entre o artesão profissional e a criança ou adolescente. É importante que o próprio adulto tenha "prazer" no trabalho que ele divide com a criança ou - adolescente e que as crianças e os adolescentes possam ter a experiência de ter que seguir regras (de trabalho) que não são colocadas por um adulto de forma arbitrária, mas que resultam do próprio "material de trabalho", como, por exemplo, a necessidade de seguir uma determinada ordem no processo de trabalho para alcançar o resultado desejado (Bouguereau, 2002) .

Engeral, as crianças e os adblescentes têm a possibilidade de encontrar nos diferentes lugares fora da école, pessoas que não se encontram no discurso pedagógico ou psicológico (como, por exemplo, as pais acolhedores, as empregadores, vizinhos das alojamentos notumos, viajantes no trem). Assim os encontros não são carregados de preconceitos (diagnósticos) e de expectativas de mudança, pois também em Bonneuil - apesar de todas as precauçães - tais preconceitos e expectativas não podem ser inconscientemente sempre evitados. Fora da école as crianças e os adblescentes têm, assim, a possibilidade de comportar-se de modo diferente e de não reproduzir as estruturas freqüentemente devoradoras que determinam as relações com os pais ou "acompanhantes" . Assim eles podem libertar-se parcialmente tão bem das antigas imagens do eu, que seus próprios pais mal podem reconhecê-los nas narrativas (sdore eles).

Além disso, as crianças e as adolescentes vêem-se confrontados fora da école repetidas vezes com acontecimentos inesperados, que a vida tem à disposição e que em parte podem ser arriscados. Mas, se esses dbstáculos são ultrapassados - como provas que têm que ser superadas - eles podem contribuir para reatual izar a força separadora de um limite simbólico e sustentar dessa forma a gênese do sujeito (Buhmann, 1990, p. 16ff) .

\section{O HOSPITAL-DIA}

No endereço "63, rue Pasteur" do subúrbio de Paris, Bonneuil-sur-Mame encontram-se três casas, dois armazéns e um grande jardim, que, juntos, constituem o centro de Bonneuil. Esse lugar, que é chamado de école (escola) e é oficialmente reconhecido como "hospital-dia", contém as salas para a aula e os 
ateliês (oficinas artísticas) , a cozinha com suas salas de jantar adjacentes, assim como uma parte na qual a administração está colocada. É o lugar no qual é permitido e se pode estar "da", quandonão se está "fort".

Este também é o lugar no qual a "loucura" pode ser vivida (quase sem acompanhamento de psicofármacos), no qual a "loucura" pode conseguir uma escuta e onde lhe são concedidos também como expressões (aparentemente) incompreensíveis - um lugar e um sentido. Contudo também na école o gozo da "loucura" está sujeito a limites, pois há duas regras básicas que têm que ser respeitadas por todos: "Deixar o outro viver e dar e receber sem parasitar" (Mannoni, 1970-73, p. 239) .

Em razão da permanente oscilação entre a école e outros lugares que pertencem a Bonneuil ou são independentes da instituição, das 37 crianças e adblescentes que Bomeuil recebe, somente de 25 a 30 passam, durante a semana, uma parte do dia au o dia inteiro na école. cerca de quarenta adultos são funcionários. Além disso, há quase a mesma quantidade de estagiários. De acordo com o conceito, as funcionários e estagiários também não estão presentes diariamente; durante o dia ficam no máximo de 35 a 40 adultos em Bonneuil. Assim para cada criança ou adolescente há, no mínimo, um adulto.

A vida na école acontece entre 8 h30 e 17h. O decorrer do dia é dividido em duas partes: Pela manhã acontece a aula. A tarde é reservada aos ateliês. No meio, há o almoço coletivo: às 12h se reúnem na cozinha, nas salas de jantar adjacentes ou no quintal na frente da cozinha, todos os que nesse dia estão presentes. Todos contribuem, com suas respectivas habilidades, arnumando as mesas, distribuindo a comida, oferecendo um certo silêncio aos outros que comem (o que não é sempre bem-sucedido) , tirando as mesas e lavando a louça. Em seguida, há uma pausa até 14h, durante a qual ocorre uma multiplicidade de encontros e conflitos entre as crianças e os adblescentes com os adultos e entre as adultos. Na pausa acontece "tudo e nada" : joga-se, movimentase, disate-se, chora-se, ri-se, empurra-se, luta-se, bate-se, avesemúsica, bebe-se café, corre-se, conversa-se etc.

O "DIREITO À RECUSA"

Em Bonneuil existe o "direito à recusa" (Mamnoni, 197073, p. 240) , o que compreende, entre outros, o direito de recusar a participação na aula ou outras atividades uma vez ou por um longo período, precisamente porque a recusa representa fre- 
qüentemente a primeira tentativa de uma expressão do desejo. Muitas das crianças e adolescentes passam por esses períodbs de recusa ou fuga permitidos e explicitamente percebidos, antes que eles aprendam a expressar seus desejos por palavras.

As crianças e os adblescentes que não participam da aula ou de outras atividades têm muitas possibilidades e lugares para se entreter. A cozinha é um dos lugares mais cobiçados. Lá é preparado o almoço, pela manhã, uma atividade da qual se pode participar ajudando ou que simplesmente é útil para doservar os que estão trabal hando ou para encontrar outros. O grande jardim e as muitos corredbres, escadas e cantos oferecem lugares de recolhimento igualmente populares. É de grande importância que haja sempre um número suficiente de adultos "livres" à disposição para também poderem oferecer à "louarra" a possibilicade de uma escuta ou um diálogo dentro desses "espaços".

\section{A "CAUSETTE"}

Mas os diálogos apenas podem acontecer quando se conversa, ou seja, quando as crianças e os adolescentes - também quando eles mesmos não falam - se encontram em um "campo de linguagem" (Mannoni, 1970-73, p. 240) ou em um bain de langage, (banho de linguagem) (Buhmann, 1990, S. 21). É característico desse banho de linguagem que os adultos mantenham um "rio corrente de linguagem" (idem) (o que não significa que ficar calado seja proibido) , do qual as crianças e os adolescentes possam fazer parte.

A relevância do banho de linguagem torna-se particularmente clara nas reuniões gerais, nas quais uma vez por semana todas as crianças e os adblescentes reúnem-se com alguns adultos na causette (hora do bate-papo) , que acontece diariamente antes do início da aula. Para Mannoni a importância da causette consiste em "determinar diariamente para a criança o contexto no qual o decorrer do seu dia acontecerá. Partindo de um mínimo de conversação entre os adultos, as crianças aprendem a se orientar em referência ao desejo do outro. Quando eles se sentem interpelados pelo que é dito, eles podem, quando não se conta com isso, começar a falar. A palavra é o que a criança tem que capturar. Quando nós exigimos a palavra da criança, nós fazemos o mesmo que a fonoaudiologia [... ] 0 que a criança [...] precisa, é, encontrar-se em um espaço em que os efeitos da fala têm o seu lugar" (Mannoni, apud Buhmann, 1990, p. 22) .

Na causette é fomecido por um lado juntamente com as crianças e os adolescentes um plano de trabaIho para o período da manhã. A causette marca com isso um enquadre no qual, em seguida, a leitura, a escrita e a contagem podem ocupar um lugar. Por autro lado, são discutidos também os acontecimentos atuais, de dentro de Bonneuil e no mundo. Um tema importante para a conversa é a presença e a ausência, sobretudo das crianças e os adblescentes, como, por exemplo, a estada futura (ou atual) de uma criança ou 
adolescente na província, na casa da sua família acolhedora, ou seu regresso. Dessa forma as crianças e as adolescentes presentes ficam sabendo que os ausentes continuam a existir nas memórias e nas narrativas dos presentes, que eles (os ausentes) são importantes (para os presentes), ou seja, que é concedido a eles um lugar como sujeito na ordem simbólica. Além disso, os relatos daqueles que retomam permitem àqueles que ainda não estiveram "fort" sonhar com uma vida fora do dia-a-dia de Bonneuil. Assim, pode ser despertado o desejo para arriscar-se mesmo nessa "aventura", no conhecimento possível de que pode-se sobreviver à separação momentânea de Bomneuil e dos pais, sem que os pais ou elas mesmas (as crianças) se despedacem (Buhmann, 1990, p. 23ff) .

\section{OS ADULTOS}

Bomeuil oferece não somente às crianças e aos adolescentes um "lugar para viver", mas também aos adultos que trabalham lá. É crucial aqui que as crianças e os adolescentes não desempenhem (ou não devam desempenhar) uma função que dê sentido à própria existência dbs adultos (a da instituição) , pois a estnutura da instituição estourada oferece aos adultos a possibilidade, tanto dentro quanto fora de Bonneuil, de seguir os próprios desejos (désirs) que sejam essenciais para eles mesmos. Isso porque em Bonneuil não se coloca (ou não se deveria colocar) - como na maioria das instituições - em primeiro plano o funcionamento eficiente e sem atritos e os adultos não são reduzidos a uma função administrativa; existe para eles também um lugar para atividades criativas, com tempo para sonhos e por isso existe um espaço no qual eles também podem aparecer enquanto sujeitos desejantes (Lérès, 2000; Mannoni, 1976-78, p. 51). Em Bonneuil se diz: "Onn'est pas làpour les enfants, cnest làavec les enfants!", ar seja, "Não se está lá para as crianças, mas sim com as crianças". Uma parte da vida é compartilhada em conjunto aqui. Mas para que algo comum possa ser desenvolvido com as crianças e os adolescentes tem que ser evitado o risco de uma relação imaginária, dual, narcísica e "sufocante" entre os adultos e as crianças e os adolescentes. Por isso, em Bonneuil tenta-se evitar - tanto no plano emocional como no plano econômico - uma dependência existencial dos adultos em relação às dificuldades nas quais as crianças e os adolescentes se encontram. Por isso nenhum adulto pode trabalhar mais do que quatro dias por semana em Bonneuil muitos passam até mesmo somente um ou dois dias lá e trabalham parcialmente em outro lugar. 
Do mesmo modo é muito importante que os adultos tenham a possibilidade de desenvolver questões próprias de pesquisa que podem ser trabal hadas nas reuniões e grupos de trabalho. Por meio dessas questões de pesquisa, o encontro com as crianças e os adolescentes pode ser recheado com interesses e desejos próprios, em vez de ser sufocado pelo desejo narcísico de ser uma querida (ou a mais querida) pessoa de referência para uma criança ou um adolescente, porque tais desejos narcísicos podem facilmente - na forma de uma relação imaginária dual - converter-se em uma armadilha da qual as crianças e os adolescentes não podem mais sair como sujeitos. Por isso as questões de pesquiisa e os interesses próprios dos adultos podem e devem intervir como terceira instância (castradora) e quebrar passíveis relações "sufocantes" duais entre eles e as crianças (e dessa forma também entre eles e a instituição) . (Lajonquière \& Scagliola, 1998, p. 26-34; Lérès, 2000) .

Nesse contexto, torna-se também evidente como é importante que os adultos em Bomeuil tenham a possibilidade de se ocupar de atividades que lhes dão prazer. Por isso não há em Borneuil - embora aqui trabalhem psicólogos, educadores, professores, psiquiatras, estagiários e autros, que não têm nenhuma formação - à exceção de alguns casos, uma divisão fixa, de acorob com a área de trabalho. Em princípio, toobs são conjuntamente responsáveis por todos os tipos de trabalho. Isso significa para os funcionários que eles podem e devem repetidas vezes perguntar a si mesmas quais são seus próprios desejos em relação às atividades, o que também não é sempre fácil para sujeitos mais "maduros" . No entanto, isso não significa que eles podem fazer simplesmente o que quiserem em determinado momento, porque o mesmo que se aplica às crianças e aos adblescentes vale para os adultos: que os projetos iniciados (normalmente) somente devem ser terminados, após alcançar o dbjetivo aspirado.

Além das crianças, adolescentes e funcionários, também os estagiários - camo todos os recém-chegados - são convidados a expressar plenamente seus próprios desejos, porque eles devem procurar, no momento da chegada, um lugar próprio, que não é dado antecipadamente, em Bomevil: Il faut se faire sa place ici! (Há que se conseguir aqui seu próprio lugar!) (Bnumer, 1984, p. 19) é o lema que desperta em muitos inicialmente a impressão de se sentirem perdidos e não saberem direito onde ficar. Mas essa dificuldade é suportada de forma consciente no conceito de instituição estourada, porque assim (pela superação dessa dificuldade) a instituição é questionada permanentemente e se impede sua cristal ização. Acredita-se que somente pelos olhares "virgens" dos recém-chegados alguns problemas podem ser percebi- 
dos ou podem ser doservados de forma diferente.

A vida em Bonneuil é enriquecida e mantida viva também pelo fato de muitos dos estagiários, mas também dos "permanentes", ou seja, os funcionários fixos, virem de outros países. Mesmo que alguns desses adultos falem pouco ou mal o idioma francês, isso não atrapalha, muito pelo contrário (isso é enriquecedor) . Por um lado, eles podem ajudar às crianças e os adolescentes que querem aprender um outro idioma e, por outro, podem - justamente por não falarem bem o francês - dar a possibilidade a alguns deles (as crianças e as adblescentes) de exercer o papel de professores (da língua francesa) e se experimentar em uma outra posição. Particularmente, esse momento pode tornar-se também muito produtivo, se crianças e adolescentes que aprendem (só agora) a se apropriar da língua, vivenciem como alguns adultos têm que superar dificuldades semelhantes (Geoffroy, 2002, p. 12ff).

Além disso, deve ser apontado que o relacionamento das crianças e dos adolescentes com os adultos pode contribuir para a repetição do "Jogo do Fort-Da" em diferentes níveis, porque enquanto os "permanentes" estão há anos "da" (também quando eles não estão presentes diariamente) , os estagiários estão, em regra, mais rápido novamente "fort" e ocupam-se de seus próprios desejos em atro lugar. Assim, as cartas e fotos, as narrativas sobre eles e as visitas (mútuas) servem para manter as lembranças (deles) vivas e para simbolizar essas experiências de separação. Ao mesmo tempo, a partida deles pode sustentar o sonho de uma vida fora do dia-a-dia de Bonnevil.

\section{A AULA}

No período da manhã, realiza-se a aula em Bonneuil, em muitos pequenos grupos diferentes de trabalho que se orientam de acordo com as habilidades e desejos das crianças e dos adolescentes. Em Bonneuil aplica-se o princípio de que são dadas boas condições de aprendizagem quando o adulto não se coloca na posição de já saber tudo, mas sim quando ele pode vivenciar algo novo junto com a criança ou o adolescente.

Mamnoni colocou-se, por um lado, firme na luta para deixar aberta a possibil 7 idade às crianças e aos adblescentes de participar - pela escola à distância ou por duas professoras, funcionárias públicas -, do programa escolar oficial, porque àqueles que cumprem esse programa com sucesso é dada a chance de entrar (ou entrar de novo) na formação educacional "normal" e poder rela- 
cionar isso à sua biografia. Além disso, a escola à distância cumpre duas funções importantes: primeiramente eles têm que ser aprovados nos exames finais. Esses exames estão sujeitos a determinadas leis, que introduzem, exatamente como o "Não-doPai" na fase edípica, uma castração simbólica ou reatualizam a força separadora de um limite simbólico. Assim podem abrir para as crianças e os adolescentes um acesso ao simbólico ou ampliá-1o. Em segundo lugar, a escola à distância pode freqüentemente desempenhar a função de uma terceira instância exterior que pode ser solicitada em caso de conflitos entre o aluno e o adulto que o ajuda (nas tarefas), para quebrar o conflito paralisado binário entre eles (Buhmann \& Keimig, 1991, p. 111; Mannoni, 1995, p. 75) .

Por outro lado, têm que ser encontrados em Bonneuil caminhos de aprendizagem altemativos e fantasiosos para aquelas crianças e adblescentes que têm grandes dificuldades de aprendizageme, por isso, não participam do programa de escola à distância. Também por isso a leitura, a escrita e a contagem não podem ser os objetivos primários da aprendizagem, porque uma criança que não pode simbolizar experiências de separação, também não poderá, por exemplo, escrever, porque a escrita pressupõe a habilidade de diferenciar, au seja, de separar, a palavra falada e escrita.

É também crucial que a aprendizagem não se limite ao escolar, pois uma aprendizagem artesanal é, do mesmo modo, avaliada como importante. Além disso, as experiências que algumas crianças e adolescentes adquirem durante o travail à I'extérieur e em outros lugares fora de Bonneuil, ajudam freqüentemente a superar os "bloqueios de aprendizage". O incentivo de querer entender melhor alguma coisa, de poder contar dinheiro no caixa, de poder decifrar os nomes das estações de metrô ou de poder conversar com outras crianças ou adolescentes sobre histórias em quadrinhos, pode transformar-se em uma força motriz. Algumas crianças e adolescentes que recusam por um tempo completamente a escola, redescobrem-na depois dessas experiências, mas diferentemente, isto é, ligada a um objetivo (Bouguereau, 2002) .

\section{OS ATELIÊS}

Os ateliês (oficinas artísticas) são espaços nos quais a fantasia e o brincar têm uma grande importância. Eles são mais do que pura atividade de lazer e também não têm um caráter terapêutico. As oficinas artísticas são pensadas, entre autras coisas, como 
passibilidade de se descobrir novas interesses e se experimentar. Dentro dos ateliês, ajjos enquadres são marcados por rituais de início e fim, as crianças e os adolescentes podem exercitar em uma atividade, a habilidade de se engajar, ou seja, de realizar objetivos de acordo com suas habilidades. Esse "engajamento" já pode ser também a tentativa de participar repetidas vezes de um ateliê por um determinado período, sem atrapalhar (Lérès, 2000, p. 314-17) .

Estende-se a oferta nas oficinas artísticas porque os ateliês podem aceitar funções bem diferentes. As ofertas são: música, pintura, dança, teatro, marionete, canções latinoamericanas, mosaico, argila, secret du nombre (segredo do número), contos de fada, fotografia a cul inária até andar de bicicleta, futebol, natação, conserto debicicletas, aridados com a horta etc. É dada a passibilidade para que todo adulto também funde um novo ateliê (Geoffroy, 2002, p. 18).

\section{UM TRAJETO NO}

\section{CAMINHO DO DESEJO}

O permanente ir e vir prepara as crianças e os adolescentes para deixar Bonneuil (que numca se cansa de se referir como lugar de passagem) algum dia para sempre. Isso porém não exclui que, sobretudo em um primeiro momento (depois da saída), seja dada uma ajuda para alguns adolescentes ou jovens adultos. Mas o que aconte- ce depois e como eles se arranjam na sociedade, fica em aberto (Mannoni, 1995, p. 129-69). Mas como Mannoni afirma, o essencial é "que seja dada a essas crianças até lá a oportunidade de percorrer um determinado trajeto no caminho do desejo. Até então passavam-se por mortos, para evitar seu próprio desejo. A partir de uma determinada etapa, eles aceitam o risco. Talvez porque conseguimos não desejar em seu lugar" (Mannoni, 1976-78, p. 53).

Há mais de trinta anos Bonneuil tenta, como instituição estaurada, combater uma - como Mannoni a chama - Sklerose institucional, para proporcionar não somente às crianças e aos adolescentes, mas também aos adultos que lá trabaIham, um trajeto no caminho do desejo. Contudo, uma instituição estourada permanece uma instituição. Isso significa que ela nunca poderá se libertar completamente das exigências sociais en relação às instituições e das contradições que estão ligadas a essas exigências e que se manifestam sobretudo na luta contra restrições econônicas e administrativas. Especialmente desde a morte de Maud Mannoni, em março de 1998, Bomeuil se vê não somente carregada por causa do luto em relação à sua morte, mas também se vê exposta a uma maior pressão financeira elarocrática por causa da ausência de uma influente personalidade - nos círculos políticos - e da ausência da principal defensora de Bomeuil.

Ao mesmo tempo, vinha ocorrendo, nos últimos anos, uma lenta 
mudança de geração. Novos empregados e estagiários (que são marcados por outras razões históricas e políticas, diferentes da geração de 68) trazem novas questões, idéias e forças resistenciais que não somente podem ser integradas pela estnutura aberta e experimental, mas que representam a condição mesma para a continuação da existência de Bomneuil como instituição estarrada, porque, apesar de toolos os efeitos institucionalizantes (que requerem uma análise separada, cf. Geoffroy, 2002, p. 125-41), consegue, com base no conceito de instituição estourada, continuar a ser um lugar onde são colocadas questões, são realizadas pesquisas e podem ser vividas experiências.

\section{REFERÊNCIAS BIBLIOGRÁFICAS}

Baguereau, J.-L. (2002). Travail à I 'extériar. Memuscrito não publicado. Paris.

Brunner, K.-M. (1984) . "Recht auf Abweichung. Maud Mannoni Konzept einer Gesprengten Institution". In: Psychologie undcesellschaftskritik. 8 (4) , 8-23.

Buhmann, C. (1990) . "Bonneuil - ein Ort zum Leben für Kinder in Schwierigkeiten. Erfahnungen in der gesprengten Institution". In: Arbeitshefte Kinderposychoanalyse, 11/12, 9-28.

(1994). "Maud Mannoni und die Versuchsschule Bomeuil - Biographische Hintergründe der gesprengten Institution". In: Arbeitshefte Kinderpsychoanalyse, 18, 35-52.

Buhmann, T \& Keimig, U. (1991) . "Trennungen - ein Briefwechsel über eine besondere psychoanalytische Praxis in der Versuchsschule Bonneuil". In: S. Becker
(Hrsg. ) . Psychase und Grenzen. Zur endlichen und unendlichen psychoanalytischen Sozialarbeit mit psychotischen Kindem, Irgendlichen, jungen Erwachsenen und ihren Familien. Tübingen: Diskord.

(1991) . Das Unzbehagen der Gesch-

lechter (K. Menke, Übers. ) . Frankfurt/M. : Suhrkamp. (Publicação original 1990: Gender Trouble) .

Butler, J. (1995) . Körper von Gewicht. Die diskursiven Grenzen des Geschlechts (K. Wördermann, Übers. ) . Frankfurt/M. : Suhrkamp. (Publicação original 1993: Bodies that Matter).

Fleur, F. , Geoffroy, M. A. (2000). Leroy, D. \& Seligman, C. Janeiro. Manuscrito não publicadb. Paris.

Freud, S. (1920). Jenseits des Lustprinzips. In: Cesammelte Werke 13 (p. 1-69). Frankfurt/M: Fischer.

Geoffroy, M. A. (2002) . Die Un-Ordmung des hehnsinns. Seine Institutionalisienungund das Prinzip der "gesprengten Institution" der École Expérimentale de Bomevi 7-sur-Marne. Dissertação não publicada. Freie: Universidade de Berlim.

Kupfer, C. \& Fleck, L. B. (1998) . "Conversando sobre as análi.ses das crianças de Borneuil". Entrevista com Alain Vanier 1. In: L. de Lajonquière \& M. C. Kupfer (Hrsg. ) . Estilos da Clínica. Revista sobrea Infância com Problemas. Dossiê: A Psicanálise e a Educação em Bonnevi I. Utra escola para os excluídos. [NNo 4] , 3 (1) , 41-46.

Lajonquière, L. de \& Scagliola, R. (1998) . "Conversando sobre Bonneuil. Entrevistas com Maud Mannoni, Marie-José Richer-Lérès e Lito Benvenutti". In: L. de Lajonquière \& M. C. Kipfer (Hrsg. ) . EStilos da Clínica. Revista sobre a Infância com Problemas. Dossiê: A Psicanálise e a Educação em Bonnevi l. Una escola para os excluÍdos. [NN 4] , 3 (1) , 20-40.

Lérès, M. -J. (2000) . "L'expérience de Bonneuil: Un lieu pour vivre, un lieu pour apprendre". In: C. Boukdbza. Ai en est la psychanalyse? Psychanalyse et figures de la 
modemité (p. 312-17) . Ramonville SaintAgne: Erè̀s.

(2002) . Palestra de 10 de abril de 2002, realizada na Universidade de Paris VII, Denis Diderot. Transcrição não publicada. Paris.

Mannoni, M. (1972) . Das zurückgebliebene Kind und seine Mutter (K. Bischoff \& H. J. Grune, Übers. ) . Olten: Walter. (Bublicação original 1964: "L'enfant arriéré et samère") .

- Der Psychiater, sein Patient und die Psychoanalyse. (K. Bischoff \& H. -J. Gnune, Übers.) . Olten: Walter. (Publicação original 1970: "Lepsychiatre, son <fau et lapsychanalyse") .

(1978) . Ein Ort zum Leben. Die

Kinder von Bonneuil, ihre Eltem und das Team der "Betreuer". (G. Osterwald, Übers.) . Frankfurt/M. : Syndikat. (Bublicação original 1976: "Un lieu parr vivre. Les enfants de Bonnevill, leurs parents et I'équipe des soignants') .

(1983). "Scheißerziehung". Von der Antipsychiatrie zur Antipädagogik. (G. Osterwald, Übers. ) . Frankfurt/M. : Athenäum. (Publicação original 1973: "Éducation impossible") .

(1995) . Les mots ant un poids. Ils sont vivants. Que sont devenus nos enfants "faus"? Paris: Denoël.

Nasio, J.-D. (1988) . Enseignement de 7 concepts cruciaxdelapsydaralyse. Paris: Payct.

Roedel, J. (1986) . Das hei lpädagogische Expe riment Bonnevil und die Psychoanalyse in Frankreich. Theorie und Praxis einer Einrichtung fürpsychischs schuergestörte Kinder. "Psychoanalytische Reflexion und theoretische Verfahren in der Pädagogik" , Band 15. (Hrsg.: A. Leber) . Frankfurt/M. : Fachbuchhandlung für Psychologie. Verlagsabteilung.

Ruhs, A. (1980) . "Die Schrift der Seele. Finführung in die Psychoanalyse nach Jacques Iacan". In: Psyche. 34 (10) , 885-909.

Vanier, A. (1998) . Lacan. Paris: Les Belles Iettres.
NOTAS

${ }^{1}$ Last but not least - último, mas não menos importante. (N. da T.)

2 Erste Bezrgsperson significa a primeira pessoa de referência, que pode ser a mãe, o pai au alguém importante para a criança nos primeiros anos de vida. Bezugsperson significa uma pessoa de referência em geral, ou seja, alguém importante mais tarde na vida. (N. daT.)

${ }^{3}$ No original temos a palavira Zersprengung, que tem a mesma raiz da palavra gesprengt (estarrada ). Escolhi a palavra estarro para manter a mesma relação proposta pela autora. (N. daT.)

${ }^{4}$ Enbora eu considere problemático e veja a necessidade de reformular não somente as idéias falocêntricas da teoria de Freud e Lacan (cf. aqui p.e. Butler, 1990-91; 1993-95), mas também os efeitos (entre outros, dados pela pressão heterossexual) que eles têm na prática de Bonneuil, eu me limito nesse artigo à representação dos elementos psicanalíticos que representam um impulso emancipatório para o trabalho em Bonneuil.

${ }^{5}$ Aqui nós vemos que de acordo com Lacan (em sua perspectiva falocêntrica) trata-se sempre da identificação do menino com o pai, pois uma identificação da menina com o pai normalmente não é prevista.

${ }^{6}$ Nome alterado.
Recebidb em janeiro/2004. Aceito em março/2004. 